\title{
The effect of dexmedetomidine on intraoperative blood glucose homeostasis: secondary analysis of a randomized controlled trial
}

\author{
Chun-Jing Li ${ }^{\dagger}$, Bo-Jie Wang ${ }^{\dagger}$, Dong-Liang Mu ${ }^{*}$ and Dong-Xin Wang
}

\begin{abstract}
Purpose: To investigate the effect of dexmedetomidine on intraoperative blood glucose hemostasis in elderly patients undergoing non-cardiac major surgery.

Methods: This was secondary analysis of a randomized controlled trial. Patients in dexmedetomidine group received a loading dose dexmedetomidine $(0.6 \mathrm{\mu g} / \mathrm{kg}$ in $10 \mathrm{~min}$ before anaesthesia induction) followed by a continuous infusion $(0.5 \mathrm{\mu g} / \mathrm{kg} / \mathrm{hr})$ till $1 \mathrm{~h}$ before the end of surgery. Patients in control group received volumematched normal saline at the same time interval. Primary outcome was the incidence of intraoperative hyperglycemia (blood glucose higher than $10 \mathrm{mmol} / \mathrm{L}$ ).

Results: 303 patients in dexmedetomidine group and 306 patients in control group were analysed. The incidence of intraoperative hyperglycemia showed no statistical significance between dexmedetomidine group and control group $(27.4 \%$ vs. $22.5 \%, \mathrm{RR}=1.22,95 \% \mathrm{Cl} 0.92-1.60, P=0.167)$. Median value of glycemic variation in dexmedetomidine group (2.5, IQR 1.4-3.7, mmol) was slightly lower than that in control group (2.6, IQR 1.5-4.0, $\mathrm{mmol}), P=0.034$. In multivariable logistic analysis, history of diabetes (OR $3.007,95 \% \mathrm{Cl} 1.826-4.950, P<0.001$ ), higher baseline blood glucose (OR 1.353,95\%Cl 1.174-1.560, $P<0.001)$ and prolonged surgery time (OR 1.197, $95 \% \mathrm{Cl} 1.083-1.324, P<0.001$ ) were independent risk factors of hyperglycaemia.
\end{abstract}

Conclusions: Dexmedetomidine presented no effect on intraoperative hyperglycemia in elderly patients undergoing major non-cardiac surgery.

Trial registration: Present study was registered at Chinese Clinical Trial Registry on December 1, 2015 (www.chictr. org.cn, registration number ChiCTR-IPR-15007654).

Keywords: Dexmedetomidine, Intraoperative hyperglycemia, Elderly, Non-cardiac surgery

\footnotetext{
* Correspondence: mudongliang@icloud.com

Department of Anesthesiology, Peking University First Hospital, Beijing, China
}

(C) The Author(s). 2021 Open Access This article is licensed under a Creative Commons Attribution 4.0 International License, which permits use, sharing, adaptation, distribution and reproduction in any medium or format, as long as you give appropriate credit to the original author(s) and the source, provide a link to the Creative Commons licence, and indicate if changes were made. The images or other third party material in this article are included in the article's Creative Commons licence, unless indicated otherwise in a credit line to the material. If material is not included in the article's Creative Commons licence and your intended use is not permitted by statutory regulation or exceeds the permitted use, you will need to obtain permission directly from the copyright holder. To view a copy of this licence, visit http://creativecommons.org/licenses/by/4.0/ The Creative Commons Public Domain Dedication waiver (http://creativecommons.org/publicdomain/zero/1.0/) applies to the data made available in this article, unless otherwise stated in a credit line to the data. 


\section{Introduction}

Glucose homeostasis is profoundly disrupted in perioperative settings which is mainly manifested as hyperglycemia and glycemic variability [1]. The incidence of intraoperative hyperglycemia varies from $3 \%$ in non-diabetic patients to $15.3 \%$ in diabetic patients [2]. It reaches up to $49 \%$ in patients who undergoing major non-cardiac surgery [3]. More than $90 \%$ of patients suffer glycemic variation with a median magnitude of $5.5 \mathrm{mmol} / \mathrm{L}$ during surgery [4]. Both hyperglycemia and magnitude of glycemic variation are related with poor patient's outcome, such as increased risk of complications (i.e., delirium, infection, acute kidney injury, atrial fibrillation, and 30-day readmission rate) and mortality [3, 5-10].

Surgery related stress response is considered as the key factor of intraoperative dysglycemia [11]. Surgery enhances sympathetic stimulation and subsequently increases levels of the hormones promoting glycogen synthesis, such as catecholamines, cortisol, glucagon, and growth hormones $[11,12]$. This escalation leads to an increase in endogenous glucose production via gluconeogenesis and glycogenolysis. Stress response also triggers excessive elevation of circulating proinflammatory cytokines (i.e., interleukins and tumor necrosis factor) [11]. These cytokines result in transient insulin resistance and impairment of insulin signaling pathway which impede glucose metabolism and utility $[11,13]$.

Dexmedetomidine is a highly selective $\alpha-2$ adrenergic agonist. Available evidences showed that perioperative application of dexmedetomidine could inhibit stress response and decrease the concentration of miscellaneous stress modulators, i.e., catecholamine and cortisol [14]. In surgical patients (i.e., spine and abdominal surgery), dexmedetomidine could decrease the incidence of hyperglycemia and alleviate glycemic variation [15-17]. However, opposing data indicates that the role of dexmedetomidine in glycemic control is uncertain. In a dose-response analysis, lower dose of dexmedetomidine decreased occurrence of hyperglycemia but higher dosage increased the risk of hyperglycemia in patients undergoing major gastrointestinal surgery [18]. This phenomenon was also observed in pediatric surgical patients $[19,20]$. Animal studies showed that dexmedetomidine elevated glucose level via $\alpha-2 \mathrm{~A}$ adrenoceptor which played an important role in regulation of insulin secretion and sympathetic output $[21,22]$.

Present study was designed to investigate the effect of intraoperative dexmedetomidine on glucose hemostasis in elderly patients undergoing non-cardiac major surgery.

\section{Materials and methods}

This was secondary analysis of a randomized controlled trial which was approved by Clinical Research Ethics
Committee of Peking University First Hospital (2015987) and registered with Chinese Clinical Trial Registry on December 1, 2015 (www.chictr.org.cn, registration number ChiCTR-IPR-15007654) [23]. Written informed consents were obtained from all patients or their legal representatives in original trial. Present study was carried out in accordance with CONSORT 2010 guidelines and Declaration of Helsinki.

\section{Participants and baseline data collection}

Elderly (age $\geq 60$ years) patients who underwent selective major non-cardiac surgery with expected duration $\geq 2 \mathrm{~h}$ under general anaesthesia were included. Patients who met any of the following criteria were excluded: (1) history of psychiatric disease, i.e., schizophrenia, epilepsy or Parkinson's disease; (2) visual, hearing, language or other barrier that impeded communication and preoperative delirium assessment; (3) history of traumatic brain injury or neurosurgery; (4) severe bradycardia (heart rate less than 40 beats per minute), sick sinus syndrome, or atrioventricular block of degree 2 or above without pacemaker; (5) severe hepatic dysfunction (Child-Pugh grade C); (6) renal failure (requirement of renal replacement therapy); (7) neurosurgery.

\section{Randomization and allocation}

In this two-armed parallel study, patients were randomized to dexmedetomidine group and control group in a ratio of $1: 1$. Random numbers were generated by using SAS statistical package version 9.3 (SAS Institute, Cary, NC, USA) with a block size of 4 .

\section{Masking}

Opaque envelopes were used to seal random number and kept by a study coordinator who was not involved in patient recruitment, data collection, perioperative care and postoperative follow-up.

Study drugs were prepared by the coordinator according to the randomization results. The study drugs, either $200 \mu \mathrm{g}(2 \mathrm{ml})$ dexmedetomidine or $2 \mathrm{ml}$ normal saline, were diluted into $50 \mathrm{ml}$ with normal saline (with a final concentration of $4 \mu \mathrm{g} / \mathrm{ml}$ for dexmedetomidine). All study drugs were colourless solution provided in syringes of the same size and brand.

Blinding method of randomization and study drug were masked from patients, investigators who performed data collection and postoperative follow-up, and related healthcare providers. Blinding was maintained throughout the study period.

To ensure patients' safety, the group allocation could be unmasked in the occurrence of severe adverse events or any unexpected deterioration in the patient's clinical status. These situations were documented in the case report forms. 


\section{Intervention, anaesthesia and perioperative care}

For patients in dexmedetomidine group, a loading dose of dexmedetomidine $(0.15 \mathrm{ml} / \mathrm{kg}$, i.e., $0.6 \mu \mathrm{g} / \mathrm{kg})$ was administered during a 10-min period before anaesthesia induction and then was followed by a continuous infusion at a rate of $0.125 \mathrm{ml} / \mathrm{kg} / \mathrm{hr}$ (i.e., $0.5 \mu \mathrm{g} / \mathrm{kg} / \mathrm{hr}$ ) till $1 \mathrm{~h}$ before the end of surgery. For patients in control group, volume-matched normal saline was administered at the same rate for the same duration.

To ensure patient's safety, study drug infusion could be slowed down or stopped by the attending anaesthesiologists in the following conditions: (1) severe bradycardia or hypotension which did not improve after routine treatment; (2) new onset atrioventricular block which did not improve after routine treatment; or (3) other conditions that anaesthesiologists considered necessary. Reasons that led to any protocol deviations were recorded. These patients were included in the intentionto-treat analysis but excluded from the per-protocol analysis.

Anesthesia induction and maintenance were administrated with propofol and sufentanil as well as inhalation of a 1:1 nitrous oxide-oxygen mixture. The aim of anesthesia depth was to maintain Bispectral index (BIS) value between 40 and 60 . Non-depolarizing neuromuscular blocking drugs (i.e., rocuronium) were administered for muscle relaxation. Fluid infusion and blood transfusion were performed according to routine practice. Blood pressure was maintained within $20 \%$ from baseline and nasopharyngeal temperature between 36.0 and $37.0{ }^{\circ} \mathrm{C}$.

All patients were transferred to the post-anaesthesia care unit (PACU) or the intensive care unit (ICU) before being sent back to general wards. Patient-controlled intravenous analgesia (PCIA) was provided for postoperative analgesia.

\section{Outcome assessment \\ Primary outcome}

Primary outcome was the incidence of intraoperative hyperglycaemia. In consistence with consensuses, hyperglycaemia was defined as serum blood glucose higher than $10 \mathrm{mmol} / \mathrm{L}$ at any time during surgery [24, 25].

Blood glucose values were read from arterial blood gas analyser $\left(\mathrm{GEM}^{\ominus}\right.$ Premier 3000, Instrumentation Laboratory, MA, USA). Blood samples were obtained from intra-arterial lines before beginning of surgery and then at 1-h interval till the end of surgery. All patients received at least two arterial blood gas testes during surgery.

\section{Secondary outcome}

Secondary endpoints included glycemic variation and risk factors of intraoperative hyperglycemia. Glycemic variation was defined as the difference between the highest and lowest perioperative glucose levels during surgery [26].

Baseline and intraoperative variables were analyzed to identify risk factors of hyperglycemia by univariate and multivariable logistic regression analysis.

\section{Statistical analysis \\ Sample size calculation}

Sample size calculation in previous study was based on the hypothesis that intraoperative dexmedetomidine could decrease the incidence of postoperative delirium (309 patients in dexmedetomidine group and 310 patients in control group) [23]. As a secondary analysis, we planned to investigate the effect of dexmedetomidine on intraoperative hyperglycemia. Thus, we excluded patients without record of intraoperative blood glucose record. We finally enrolled 303 patients in dexmedetomidine group and 306 patients in control group.

\section{Outcome analysis}

The normality of continuous data was tested in prior. Continuous data with normal distribution were compared with the independent sample T-test. Continuous data with non-normal distribution were compared with the independent sample Mann-Whitney $U$ test. Categorical data were compared with the Chi-squared test.

For primary outcome, the incidence of intraoperative hyperglycemia was presented as number (percentage). Estimated effect size was reported in the form of relative risk (RR) with 95\% confidence interval (CI) both in intention-to-treat analysis and per protocol analysis. Subgroup analyses were also tested based on age, sex, history of diabetics, site of surgery and type of surgery.

The incidence of glycemic variation was presented in number (percentage) and analysed by Chi-squared test. Univariate analysis was firstly used to analyse the underlying relationship between baseline and intra-operative variables and hyperglycemia. Variables with $P<0.1$ were entered multivariate analysis to identify independent risk factors of hyperglycemia. Intervention with dexmedetomidine was compulsorily analysed in univariate and multivariable analysis.

Statistical analyses were done with SPSS 14.0 (SPSS, Inc., Chicago, IL) and SAS 9.3 (SAS Institute, Cary, NC, USA). All tests were two tailed and $\mathrm{P}$ value less than 0.05 was considered as statistically significant.

\section{Results}

\section{Participants}

During study period, a total of 620 patients were enrolled and randomized (Fig. 1). In dexmedetomidine group, 1 patient withdrew consent before administration of study drug and 6 patients had no record of 


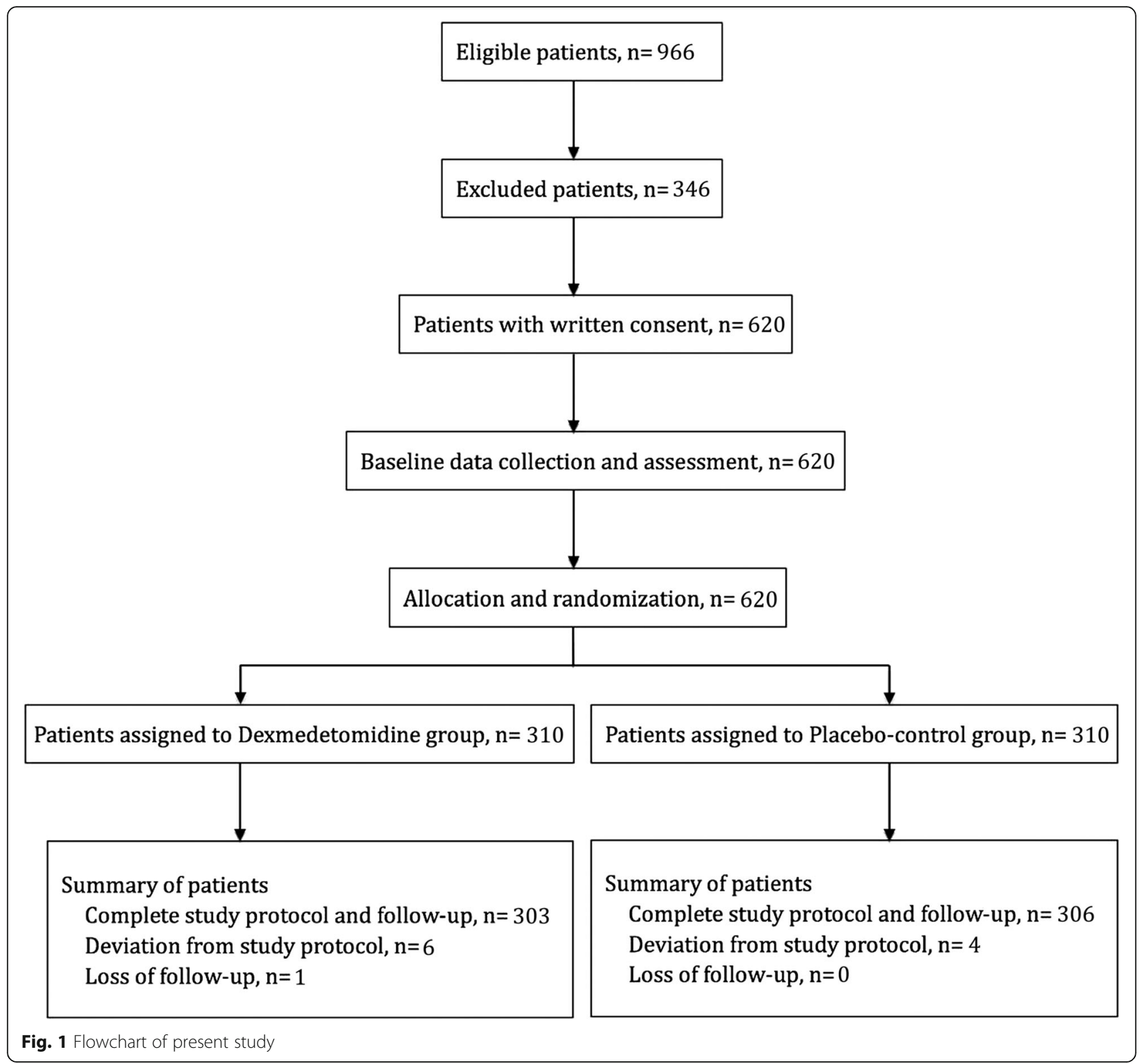

intraoperative blood glucose. In the control group, 4 patients had no record of intraoperative blood glucose. Modification of infusion rate of study drug happened in 13 patients in dexmedetomidine group and 8 patients in control group $(P=0.257)$. One patient in the control group died on postoperative day 28.

Baseline variables were comparable between the two groups (Table 1). Patients in dexmedetomidine group consumed less dosage of propofol and sufentanil than in control group $(P<0.001$ and $P=0.012$, respectively), whereas anesthesia depth was similar between the two groups $(P=0.149)$, Table 2 . Urine output was higher in dexmedetomidine group than in control group $(P<$ $0.001)$, Table 2.

\section{Primary outcome}

The median of highest blood glucose in dexmedetomidine group was 8.7 (IQR 7.7-10.2) $\mathrm{mmol} / \mathrm{L}$ whereas 8.4 (IQR 7.1-9.8) $\mathrm{mmol} / \mathrm{L}$ in control group $(P=0.474)$. The incidence of intraoperative hyperglycaemia was about $27.4 \%(83 / 303)$ in dexmedetomidine group which had no statistical difference in comparison with $22.5 \%$ (69/ 306) of control group (RR 1.22, 95\%CI $0.92-1.60, P=$ $0.167)$, Fig. 2 . The result was similar in per protocol analysis, $27.9 \%(81 / 290)$ in dexmedetomidine group vs. $22.5 \%(67 / 298)$ in control group, $\mathrm{RR}=1.242,95 \% \mathrm{CI}$ $0.939-1.644, P=0.128$.

In subgroup analysis, there was no significant relationship between dexmedetomidine and hyperglycaemia on 
Table 1 Baseline data

\begin{tabular}{|c|c|c|}
\hline Variables & Dexmedetomidine group $(n=303)$ & Control group $(n=306)$ \\
\hline Age, mean (SD), year & $69.1(6.6)$ & $69.0(6.4)$ \\
\hline $\mathrm{BMl}, \mathrm{Kg} / \mathrm{m}^{2}$, mean (SD) & $24.1(3.2)$ & $24.1(3.4)$ \\
\hline $\mathrm{BMI} \geq 30, \mathrm{n}(\%)$ & $12(4.0)$ & $12(3.9)$ \\
\hline Female, n (\%) & $179(59.1)$ & $186(60.8)$ \\
\hline \multicolumn{3}{|l|}{ Preoperative comorbidity, n (\%) } \\
\hline Hypertension & $143(47.9)$ & $144(46.7)$ \\
\hline Coronary artery disease & $43(14.2)$ & $49(16.0)$ \\
\hline Arrhythmia & $24(7.9)$ & $30(9.8)$ \\
\hline Congestive heart failure & $0(0.0)$ & $2(0.7)$ \\
\hline Stroke & $27(8.9)$ & $33(10.8)$ \\
\hline Diabetics & $70(23.1)$ & $62(20.3)$ \\
\hline Hyperlipidemia & $8(2.6)$ & $13(4.2)$ \\
\hline COPD & $4(1.3)$ & $5(1.6)$ \\
\hline \multicolumn{3}{|l|}{ ASA classification, n (\%) } \\
\hline । & $35(11.6)$ & $41(13.4)$ \\
\hline$\|$ & $240(79.2)$ & $228(74.5)$ \\
\hline III & $28(9.2)$ & $37(12.1)$ \\
\hline Baseline blood glucose, mean (SD), mmol/L & $6.0(1.9)$ & $5.9(1.5)$ \\
\hline \multicolumn{3}{|l|}{ Baseline blood glucose grade, $\mathrm{n}(\%)$} \\
\hline$\leq 6.1 \mathrm{mmol} / \mathrm{L}$ & $218(71.9)$ & $219(71.6)$ \\
\hline $6.1-7.0 \mathrm{mmol} / \mathrm{L}$ & $40(13.2)$ & $39(12.7)$ \\
\hline$\geq 7.0 \mathrm{mmol} / \mathrm{L}$ & $45(14.9)$ & $48(15.7)$ \\
\hline $\mathrm{CCl}$, median (IQR), score ${ }^{a}$ & $4(4,5)$ & $4(4,5)$ \\
\hline
\end{tabular}

$B M I$ body mass index, SD standard deviation, COPD chronic obstructive pulmonary disease, ASA American Society of Anesthesiologists, CCI Charlson Comorbidity Index, $I Q R$ interquartile range

a Score ranges from 0-37, with higher score indicating worse prognosis

predefined factors, i.e., sex, age, history of diabetic, site of surgery and type of surgery type, Fig. 2.

\section{Intraoperative glycemic variation}

The median of glycemic variation in dexmedetomidine group was slightly less than that of control group (2.5 vs. $2.6 \mathrm{mmol} / \mathrm{L}, P=0.034)$. The magnitude of glycemic variation was divided into six range groups. The frequencies were presented in Fig. 3 and showed no statistical difference between two groups $(P=0.581)$.

\section{Risk factors of intraoperative hyperglycaemia}

Both in univariate and multivariate analysis, use of dexmedetomidine was not related with hyperglycaemia (OR 1.322 , $95 \%$ CI $0.881-1.983, P=0.178)$, Table 3 . History of diabetics (OR 3.007, 95\%CI 1.826-4.950, $P<0.001$ ), higher baseline blood glucose (OR 1.353, 95\%CI 1.174$1.560, P<0.001)$ and prolonged surgery time (OR 1.197, 95\%CI 1.083-1.324, $P<0.001)$ were independent risk factors for intraoperative hyperglycemia.

\section{Discussion}

Present study found that application of dexmedetomidine had no effect on blood glucose hemostasis in elderly patients undergoing non-cardiac major surgery.

Hyperglycemia has been proposed highly related with poor patient's outcome, but the definition of intraoperative hyperglycemia is still inconclusive [3,5-10]. The following criteria has been used in literatures, such as $\geq 8.3 \mathrm{mmol} / \mathrm{L}$, $\geq 10 \mathrm{mmol} / \mathrm{L}$, and $\geq 11.1 \mathrm{mmol} / \mathrm{L}[5,24,25,27]$. The difference in definition significantly influences the homogeneity of results. In present study, we adopted $10 \mathrm{mmol} / \mathrm{L}$ as the cut-off point to diagnose intraoperative glycemia in line with guidelines and expert consensus [24, 25].

The effect of dexmedetomidine on intraoperative blood glucose is still uncertain. One meta-analysis showed that infusion of dexmedetomidine could decrease intraoperative blood glucose levels with a mean difference of $1 \mathrm{mmol} / \mathrm{L}$ in comparison with control groups, but these results presented significant heterogeneity $\left(I^{2}=97 \%\right)$ [17]. In a pilot study of diabetic patient, intraoperative dexmedetomidine infusion maintained blood glucose levels at a constant level with 
Table 2 Intra- and postoperative data

\begin{tabular}{|c|c|c|}
\hline Variables & Dexmedetomidine group $(n=303)$ & Control group $(n=306)$ \\
\hline Duration of anesthesia, mean (SD), h & $4.8(1.8)$ & $4.9(2.0)$ \\
\hline Duration of surgery, mean (SD), h & $3.6(1.8)$ & $3.6(1.8)$ \\
\hline \multicolumn{3}{|l|}{ Intraoperative drugs } \\
\hline Study drug, median (IQR), ml & $30.0(23.0,38.0)$ & $29.0(23.0,38.0)$ \\
\hline Propofol, median (IQR), mg & $817(600,1102)$ & $960(669,1320)$ \\
\hline Sufentanil, median (IQR), $\mu \mathrm{g}$ & $72.0(55.0,93.0)$ & $78.5(60.0,106.0)$ \\
\hline Use of tropisetron, n (\%) & $268(88.4)$ & $263(85.9)$ \\
\hline Use of NSAIDs, n (\%) ${ }^{a}$ & $11(3.6)$ & $10(3.3)$ \\
\hline Use of glucocorticoids, n (\%) & $298(98.3)$ & $297(97.1)$ \\
\hline Low-dose glucocorticoids ${ }^{b}$ & $295(97.4)$ & $295(96.4)$ \\
\hline High-dose methylprednisolone ${ }^{c}$ & $3(1.0)$ & $2(0.7)$ \\
\hline Average BIS value, mean (SD) ${ }^{d}$ & $50.5(3.7)(n=291)$ & $51.0(4.9)(n=294)$ \\
\hline Average MAP, mean (SD), mmHg & $79.3(20.2)$ & $79.9(22.0)$ \\
\hline \multicolumn{3}{|l|}{ Location of surgery, n (\%) } \\
\hline Intra-thoracic & $56(18.5)$ & $53(17.3)$ \\
\hline Intra-abdominal & $200(66.0)$ & $221(72.2)$ \\
\hline Spinal & $47(15.5)$ & $32(10.5)$ \\
\hline \multicolumn{3}{|l|}{ Type of surgery, n (\%) } \\
\hline Thoraco-laparoscopic & $230(75.9)$ & $248(81.0)$ \\
\hline Open thoraco-abdominal/spinal & $75(24.1)$ & $58(19.0)$ \\
\hline Total fluid infusion, median (IQR), $\mathrm{ml}^{\mathrm{e}}$ & $2300(1700,3100)$ & $2250(1600,3350)$ \\
\hline Allogenic red blood cells, n (\%) & $20(6.6)$ & $24(7.8)$ \\
\hline Urine output, median (IQR), ml & $600(300,900)$ & $400(250,650)$ \\
\hline Estimated blood loss, median (IQR), ml & $100(50,300)$ & $100(50,300)$ \\
\hline No. of patients with complications, $n(\%)^{f}$ & $72(23.8)$ & $98(32.0)$ \\
\hline Postoperative LOS, median (IQR), day & $8(6,12)$ & $8(6,11)$ \\
\hline
\end{tabular}

$S D$ standard deviation, IQR interquartile range, NSAIDs non-steroid anti-inflammatory drugs, BIS Bispectral Index, MAP mean arterial blood pressure, No. number, LOS length of stay

a Included parecoxib (40 $\mathrm{mg}$ ) or flurbiprofen axetil $(50 \mathrm{mg})$, administered before the end of surgery

${ }^{\mathrm{b}}$ Dexamethasone $(5-10 \mathrm{mg})$ or methylprednisolone $(40 \mathrm{mg})$ for the prevention of postoperative nausea and vomiting

${ }^{\mathrm{C}}$ Methylprednisolone $500-1000 \mathrm{mg}$ administered during spinal surgery

${ }^{\mathrm{d}}$ Monitored with Bispectral Index (BIS) with data collected at 1-min interval from end of anesthesia induction to end of surgery

e Included hydroxyethyl starch and/or succinylated gelatin

${ }^{f}$ Postoperative complications included delirium, ischemic cerebrovascular infarction, acute coronary syndrome, congestive heart failure, new onset atrial fibrillation, deep venous thrombosis, pneumonia, respiratory failure, asthma, acute kidney injury, and surgery-related complications (i.e., gastrointestinal hemorrhage, anastomotic leak and sepsis)

reference to baseline within $24 \mathrm{~h}$ postoperatively and lowered the incidence of hyperglycemia in comparison with control group [15]. We also noticed that the median value of glycemic variation was slightly lower than that of control group (median difference $0.1 \mathrm{mmol} / \mathrm{L}$ ) in present study, but this seemed to be no clinical relevance.

The association between dexmedetomidine and blood glucose can be influenced by the following factors. First, the effect of dexmedetomidine on blood glucose is dose dependent. In patients undergoing abdominal surgery, patients were divided into three groups and received low, medium and high dosages of dexmedetomidine respectively [18]. In low dosage group, perioperative blood glucose were well regulated in non-diabetic patients whereas higher dosages of dexmedetomidine increased the incidence of hyperglycemia and bradycardia [18]. Evidences in pediatric patients also showed that the elevation of glucose is depended on the dosage of dexmedetomidine [19]. Second, dexmedetomidine could stimulate glucose elevation via $\alpha-2 \mathrm{~A}$ receptor which might overweight its effect of stress alleviation [21, 22]. Third, high dose of dexmedetomidine increased the risk of adverse events (such as hypotension and severe bradycardia) which might induce marked hyperglycemia [28]. 


\begin{tabular}{|c|c|c|c|c|c|c|}
\hline Variables & $\begin{array}{l}\text { No. of events } \\
\text { in DEX group }\end{array}$ & $\begin{array}{l}\text { No. of events in } \\
\text { Control group }\end{array}$ & & & $\begin{array}{c}\text { Relative risk } \\
(95 \% \mathrm{CI})\end{array}$ & $\mathbf{P}$ \\
\hline \multicolumn{7}{|c|}{ 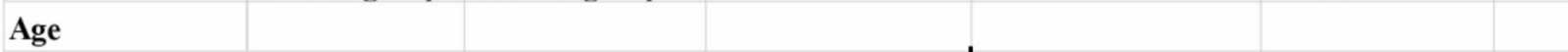 } \\
\hline Age $\geqslant 70$-year & $41 / 131$ & $26 / 126$ & & $\longrightarrow$ & $1.52(0.99,2.32)$ & 0.052 \\
\hline Age $<70$-year & $42 / 172$ & $43 / 180$ & $\longmapsto$ & $\longrightarrow$ & $1.02(0.71,1.48)$ & 0.908 \\
\hline \multicolumn{7}{|l|}{ Sex } \\
\hline Male & $55 / 179$ & $44 / 186$ & t & + & $1.30(0.93,1.82)$ & 0.129 \\
\hline Female & $28 / 124$ & $25 / 120$ & $\longmapsto$ & + & $1.08(0.67,1.75)$ & 0.741 \\
\hline \multicolumn{7}{|l|}{ Diabetics } \\
\hline Yes & $40 / 70$ & $27 / 62$ & & 1 & $1.31(0.93,1.86)$ & 0.119 \\
\hline No & $43 / 233$ & $42 / 244$ & $\longmapsto$ & + & $1.07(0.73,1.58)$ & 0.723 \\
\hline \multicolumn{7}{|l|}{ Site of surgery } \\
\hline Abdominal & $52 / 200$ & $49 / 221$ & $\mapsto$ & $\longrightarrow$ & $1.17(0.84,1.65)$ & 0.358 \\
\hline Non-abdominal & $31 / 103$ & $20 / 85$ & $\mapsto$ & $\longrightarrow$ & $1.28(0.79,2.07)$ & 0.313 \\
\hline \multicolumn{7}{|l|}{ Type of surgery } \\
\hline Laparoscopic & $62 / 230$ & $55 / 248$ & 4 & $\longrightarrow$ & $1.22(0.89,1.67)$ & 0.225 \\
\hline Open & $21 / 73$ & $14 / 58$ & $\longmapsto$ & + & $1.19(0.67,2.13)$ & 0.552 \\
\hline \multirow[t]{5}{*}{ Over all } & $83 / 303$ & $69 / 306$ & & $\longrightarrow$ & $1.22(0.92,1.60)$ & 0.167 \\
\hline & & & & & & \\
\hline & & & 0.0 & 2.0 & & \\
\hline & & & & & & \\
\hline & & & & & & \\
\hline $\begin{array}{l}\text { Fig. } 2 \text { Subgroup anal } \\
\text { subgroup analysis of } \\
\text { dexmedetomidine; } \mathrm{Cl}\end{array}$ & $\begin{array}{l}\text { of primary of } \\
\text { oredefined fa }\end{array}$ & There were $n$ & it interactions betw & $\begin{array}{l}\text { ween dexmedetomidine anc } \\
\text { ry and type of surgery type }\end{array}$ & $\begin{array}{l}\text { d hyperglycemia, } \\
\text { (All } P \text { value }>0.0\end{array}$ & $\begin{array}{l}\text { en in } \\
\mathrm{DEX}=\end{array}$ \\
\hline
\end{tabular}

In present study, we found that history of diabetics, higher baseline blood glucose and prolonged surgery time were independent risk factors of intraoperative risk factors. This result was also supported by other studies [29].
Strength of present study was a relatively large sample size than previous studies [17]. We also conducted subgroup analysis to analyze the relationship between dexmedetomidine and blood glucose in different populations.

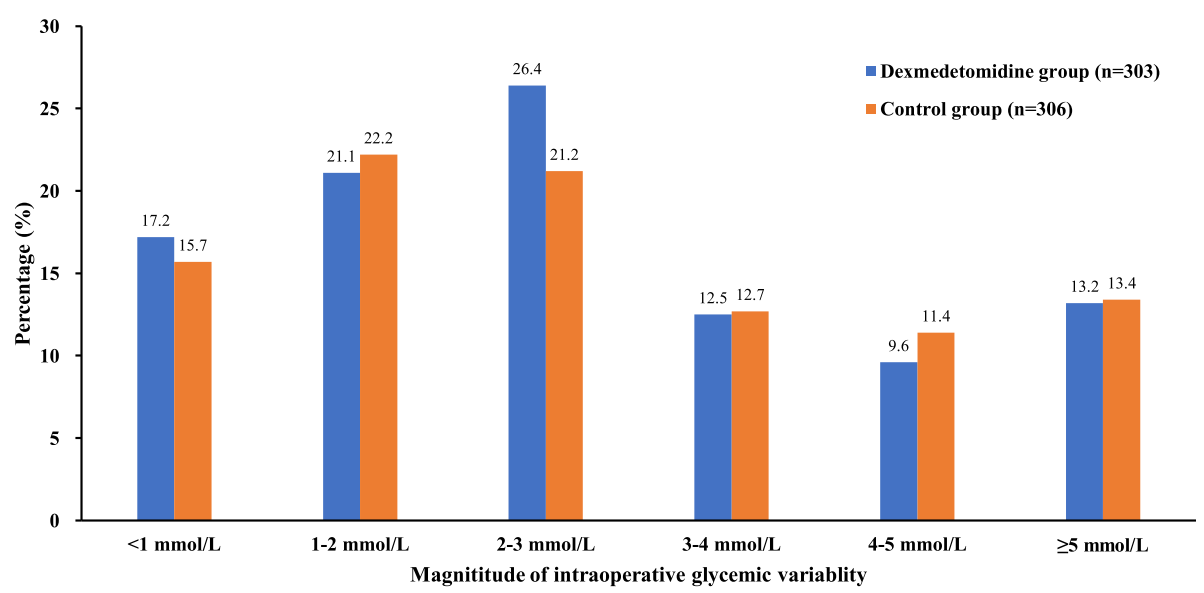

Fig. 3 Intraoperative glycemic variability. The magnitude of intraoperative glycemic variability was divided into 6 groups and the frequencies showed no statistical difference between two groups $(P=0.581)$ 
Table 3 Risk factors of intraoperative hyperglycemia

\begin{tabular}{|c|c|c|c|c|}
\hline \multirow[t]{2}{*}{ Variables } & \multicolumn{2}{|l|}{ Univariate analysis } & \multicolumn{2}{|l|}{ Multivariable analysis } \\
\hline & Odds ratio $(95 \% \mathrm{Cl})$ & $P$ & Odds ratio $(95 \% \mathrm{Cl})$ & $P$ \\
\hline History of diabetics (yes) & $4.754(3.142,7.192)$ & $<0.001$ & $3.007(1.826,4.950)$ & $<0.00$ \\
\hline ASA grade (per grade increase) & $1.397(0.950,2.054)$ & 0.089 & - & - \\
\hline Baseline blood glucose (per mmol/L increase) & $1.579(1.384,1.802)$ & $<0.001$ & $1.353(1.174,1.560)$ & $<0.00$ \\
\hline Use of dexmedetomidine (yes) ${ }^{a}$ & $1.296(0.897,1.873)$ & 0.168 & $1.322(0.881,1.983)$ & 0.178 \\
\hline Anesthesia time (per hour increase) ${ }^{b}$ & $1.174(1.070,1.289)$ & 0.001 & - & - \\
\hline Surgery time (per hour increase) ${ }^{b}$ & $1.185(1.073,1.308)$ & 0.001 & $1.197(1.083,1.324)$ & $<0.00$ \\
\hline Blood loss (per $50 \mathrm{ml}$ increase) & $1.087(1.023,1.154)$ & 0.007 & - & - \\
\hline
\end{tabular}

$\mathrm{Kg}$ kilogram, ASA American Society of Anesthesiology, Cl confidence interval

ase of dexmedetomidine during surgery was compulsorily analyzed by univariate and multivariate analysis

${ }^{b}$ There was correlation between anesthesia time and surgery time (Pearson coefficient $=0.969, P<0.001$ ). Only surgery time entered multivariate analysis

One limitation was that we excluded patients who were not suitable to receive dexmedetomidine, such as severe arrythmia and hepatic dysfunction. This excluded patients with severe disease and limited the generality of our result. Another limitation was that postoperative blood glucose was not analyzed.

\section{Conclusions}

For elderly patients undergoing major non-cardiac surgery, intraoperative administration of dexmedetomidine had no effect on the incidence of hyperglycemia. The effect of dexmedetomidine on hyperglycemia deserves further study. For example, if the dosage and administration time of dexmedetomidine will influence the incidence of intra- and post-operative hyperglycemia.

\section{Abbreviations}

BIS: Bispectral index; PACU: Post-anaesthesia care unit; ICU: Intensive care unit; PCIA: Patient-controlled intravenous analgesia; RR: Relative risk; IQR: Interquartile range; OR: Odds ratio

\section{Acknowledgments}

We appreciate Professor Xue-ying Li (Department of Biostatistics, Peking University First Hospital, Beijing, China) for her help in statistical analysis.

\section{Authors' contributions}

Chun-Jing Li and Bo-Jie Wang helped in data collection and analysis. DongLiang Mu helped in data analysis and manuscript draft. Dong-Xin Wang helped in manuscript revision. All authors read and approved the final manuscript.

\section{Funding}

This trial was supported by National Key R\&D Program of China (2018YFC2001800). The sponsors have no role in the study design and conduct; the collection, management, analysis, and interpretation of the data; or the preparation and approval of the manuscript.

\section{Availability of data and materials}

The datasets used and analysed during the current study are available from the corresponding author (DL Mu, mudongliang@bjmu.edu.cn) on reasonable request.

\section{Declarations}

\section{Ethics approval and consent to participate}

Present study was approved by Clinical Research Ethics Committee of Peking University First Hospital (2015-987) and registered with Chinese Clinical Trial
Registry on December 1, 2015 (www.chictr.org.cn, registration number ChiCTR-IPR-15007654). Written informed consents were obtained from all patients or their legal representatives in original trial.

\section{Competing interests}

The authors declare that they have no competing interests.

Received: 30 November 2020 Accepted: 20 April 2021

Published online: 07 May 2021

\section{References}

1. Duggan $E$, Chen $Y$. Glycemic management in the operating room: screening, monitoring, oral hypoglycemics, and insulin therapy. Curr DiabRep. 2019:19(11):134

2. Nair BG, Neradilek MB, Newman SF, Horibe M. Association between acute phase perioperative glucose parameters and postoperative outcomes in diabetic and non-diabetic patients undergoing non-cardiac surgery. Am J Surg. 2019;218(2):302-10.

3. Shanks AM, Woodrum DT, Kumar SS, Campbell DA Jr, Kheterpal S. Intraoperative hyperglycemia is independently associated with infectious complications after non-cardiac surgery. BMC Anesthesiol. 2018;18(1):90.

4. Sim MA, Liu W, Chew STH, Ti LK. Wider perioperative glycemic fluctuations increase risk of postoperative atrial fibrillation and ICU length of stay. PLoS ONE. 2018;13(6):e0198533.

5. Windmann V, Spies C, Knaak C, Wollersheim T, Piper SK, Vorderwulbecke G, Kurpanik M, Kuenz S, Lachmann G. Intraoperative hyperglycemia increases the incidence of postoperative delirium. Minerva Anestesiol. 2019:85(11): 1201-10.

6. Song JW, Shim JK, Yoo KJ, Oh SY, Kwak YL. Impact of intraoperative hyperglycaemia on renal dysfunction after off-pump coronary artery bypass. Interact Cardiovasc Thorac Surg. 2013;17(3):473-8.

7. Subramaniam B, Lerner A, Novack V, Khabbaz K, Paryente-Wiesmann M, Hess $P$, Talmor D. Increased glycemic variability in patients with elevated preoperative $\mathrm{HbA} 1 \mathrm{C}$ predicts adverse outcomes following coronary artery bypass grafting surgery. Anesth Analg. 2014;118(2):277-87.

8. Clement KC, Alejo D, DiNatale J, Whitman GJR, Matthew TL, Clement SC, Lawton JS. Increased glucose variability is associated with atrial fibrillation after coronary artery bypass. J Card Surg. 2019:34(7):549-54

9. Hsieh CJ. High glucose variability increases 30-day readmission rates in patients with type 2 diabetes hospitalized in Department of Surgery. Sci Rep. 2019;9(1):14240.

10. Weber $\mathrm{C}$, Schnell $\mathrm{O}$. The assessment of glycemic variability and its impact on diabetes-related complications: an overview. Diabetes Technol Ther. 2009;11(10):623-33.

11. Palermo NE, Gianchandani RY, McDonnell ME, Alexanian SM. Stress hyperglycemia during surgery and anesthesia: pathogenesis and clinical implications. Curr DiabRep. 2016;16(3):33.

12. Karayiannakis AJ, Makri GG, Mantzioka A, Karousos D, Karatzas G. Systemic stress response after laparoscopic or open cholecystectomy: a randomized trial. Br J Surg. 1997;84(4):467-71. 
13. Carli F. Physiologic considerations of enhanced recovery after surgery (ERAS) programs: implications of the stress response. Can J Anaesth. 2015;62(2): 110-9.

14. Wang XW, Cao JB, Lv BS, Mi WD, Wang ZQ, Zhang C, Wang HL, Xu Z. Effect of perioperative dexmedetomidine on the endocrine modulators of stress response: a meta-analysis. Clin Exp Pharmacol Physiol. 2015;42(8):828-36.

15. Hui Yun S, Suk Choi Y. The effects of dexmedetomidine administration on postoperative blood glucose levels in diabetes mellitus patients undergoing spinal anesthesia: a pilot study. Anesthesiol Pain Med. 2016;6(6):e40483.

16. Harsoor SS, Rani DD, Lathashree S, Nethra SS, Sudheesh K. Effect of intraoperative dexmedetomidine infusion on Sevoflurane requirement and blood glucose levels during entropy-guided general anesthesia. J Anaesthesiol Clin Pharmacol. 2014;30(1):25-30.

17. Wang K, Wu M, Xu J, Wu C, Zhang B, Wang G, Ma D. Effects of dexmedetomidine on perioperative stress, inflammation, and immune function: systematic review and meta-analysis. Br J Anaesth. 2019;123(6): 777-94.

18. Zhou W, Zhang DS, Tian SP, Tan C, Ma RR, Zhang J, Sun JH, Zhang Z. Optimal dose of dexmedetomidine for perioperative blood glucose regulation in non-diabetic patients undergoing gastrointestinal malignant tumor resection: a randomized double-blinded controlled trial. J Investig Surg. 2020:1-6.

19. Gorges M, Poznikoff AK, West NC, Brodie SM, Brant RF, Whyte SD. Effects of dexmedetomidine on blood glucose and serum potassium levels in children undergoing general anesthesia: a secondary analysis of safety endpoints during a randomized controlled trial. Anesth Analg. 2019;129(4): 1093-9.

20. Walker J, Maccallum M, Fischer C, Kopcha R, Saylors R, McCall J. Sedation using dexmedetomidine in pediatric burn patients. J Burn Care Res. 2006; 27(2):206-10.

21. Fagerholm V, Grönroos T, Marjamäki P, Viljanen T, Scheinin M, Haaparanta M. Altered glucose homeostasis in alpha2A-adrenoceptor knockout mice. Eur J Pharmacol. 2004;505(1-3):243-52.

22. Savontaus E, Fagerholm V, Rahkonen O, Scheinin M. Reduced blood glucose levels, increased insulin levels and improved glucose tolerance in alpha2Aadrenoceptor knockout mice. Eur J Pharmacol. 2008;578(2-3):359-64.

23. Li CJ, Wang BJ, Mu DL, Hu J, Guo C, Li XY, Ma D, Wang DX. Randomized clinical trial of intraoperative dexmedetomidine to prevent delirium in the elderly undergoing major non-cardiac surgery. Br J Surg. 2020;107(2):e12332.

24. Cheisson G, Jacqueminet $\mathrm{S}$, Cosson E, Ichai C, Leguerrier AM, NicolescuCatargi B, Ouattara A, Tauveron I, Valensi P, Benhamou D. Perioperative management of adult diabetic patients. Intraoperative period. Anaesth Crit Care Pain Med. 2018;37(Suppl 1):S21-s25.

25. Duggan EW, Carlson K, Umpierrez GE. Perioperative hyperglycemia management: an update. Anesthesiology. 2017;126(3):547-60.

26. Sim MA, Liu W, Ng RR, Ti LK, Chew ST. Wider perioperative glycemic fluctuations increase risk of postoperative acute kidney injury: a Prospective Cohort Study. Medicine. 2015;94(44):e1953.

27. Nurok M, Cheng J, Romeo GR, Vecino SM, Fields KG, YaDeau JT. Dexamethasone and perioperative blood glucose in patients undergoing total joint arthroplasty: a retrospective study. J Clin Anesth. 2017;37:116-22.

28. Hager P, Permert J, Strömmer L. An experimental model of intestinal resection and compensated non-hypotensive blood loss. J Surg Res. 2009; 154(1):1-8.

29. Knaak C, Wollersheim T, Mörgeli R, Spies C, Vorderwülbecke G, Windmann V, Kuenz S, Kurpanik M, Lachmann G. Risk factors of intraoperative dysglycemia in elderly surgical patients. Int J Med Sci. 2019;16(5):665-74

\section{Publisher's Note}

Springer Nature remains neutral with regard to jurisdictional claims in published maps and institutional affiliations.

Ready to submit your research? Choose BMC and benefit from:

- fast, convenient online submission

- thorough peer review by experienced researchers in your field

- rapid publication on acceptance

- support for research data, including large and complex data types

- gold Open Access which fosters wider collaboration and increased citations

- maximum visibility for your research: over $100 \mathrm{M}$ website views per year

At BMC, research is always in progress.

Learn more biomedcentral.com/submissions 